\title{
The effectiveness of hydrotherapy in the treatment of social and behavioral aspects of children with autism spectrum disorders: a systematic review
}

\author{
This article was published in the following Dove Press journal: \\ Journal of Multidisciplinary Healthcare \\ 3 February 2014 \\ Number of times this article has been viewed
}

\section{Rachel Mortimer \\ Melinda Privopoulos \\ Saravana Kumar}

International Centre for Allied Health Evidence, School of Health Sciences, University of South Australia, Adelaide, SA, Australia
Correspondence: Saravana Kumar International Centre for Allied Health Evidence (iCAHE), GPO Box 247I, University of South Australia, Adelaide, SA 5000, Australia

Tel +6I 883022085

Fax +61883022766

Email saravana.kumar@unisa.edu.au
Background: Autism spectrum disorders (ASDs) are increasing in prevalence. Children with ASDs present with impairments in social interactions; communication; restricted, repetitive, and stereotyped patterns of behavior, interests, or activities; as well as motor delays. Hydrotherapy is used as a treatment for children with disabilities and motor delays. There have been no systematic reviews conducted on the effectiveness of hydrotherapy in children with ASDs.

Aim: We aimed to examine the effectiveness of hydrotherapy on social interactions and behaviors in the treatment of children with ASDs.

Methods: A systematic search of Cochrane, CINAHL, PsycINFO, Embase, MEDLINE ${ }^{\circledR}$, and Academic Search Premier was conducted. Studies of participants, aged 3-18 years, with ASDs at a high-functioning level were included if they utilized outcome measures assessing social interactions and behaviors through questionnaire or observation. A critical appraisal, using the McMaster Critical Review Form for Quantitative Studies, was performed to assess methodological quality.

Results: Four studies of varying research design and quality met the inclusion criteria. The participants in these studies were aged between 3-12 years of age. The duration of the intervention ranged from 10-14 weeks, and each study used varied measures of outcome. Overall, all the studies showed some improvements in social interactions or behaviors following a Halliwick-based hydrotherapy intervention.

Interpretation: Few studies have investigated the effect of hydrotherapy on the social interactions and behaviors of children with ASDs. While there is an increasing body of evidence for hydrotherapy for children with ASDs, this is constrained by small sample size, lack of comparator, crude sampling methods, and the lack of standardized outcome measures. Hydrotherapy shows potential as a treatment method for social interactions and behaviors in children with ASDs.

Keywords: evidence-based practice, aquatic therapy, pediatrics, secondary research

\section{Background}

Autism spectrum disorders (ASDs), including Asperger's syndrome and "atypical autism or pervasive developmental disorder - not otherwise specified," are a group of neurodevelopment disorders "defined by compositions of impairments in three domains: reciprocal social interaction, neutral verbal and non-verbal communication alongside with inflexible behavior patterns, interests and activities (DSM-IV-TR/ICD-10 [Diagnostic and Statistical Manual of Mental Disorders-IV-Text Revision/International Classification of Disease])." ${ }^{\prime 1}$ Historical prevalence reports are approximately four per 
10,000 children; ${ }^{2}$ however, more recent data suggests an increasing prevalence of one in 88 US children, or 90 per $10,000 .^{3,4}$

Whilst the diagnostic criteria for ASDs is based on social and behavioral impairments, children with ASDs may often present with motor skill difficulties and delays that may lead to decreased physical activity levels and social play. ${ }^{5-9}$ A range of treatment options are available, including behavioral therapy, sensory integration, dance and music therapies, diet modification, speech and language therapy, occupational and physical therapy, animal interaction, and pharmacological adjunct therapies..$^{3,10-12}$

Hydrotherapy has been used for musculoskeletal and neuromuscular rehabilitation for over 100 years. ${ }^{11}$ It has been shown to improve motor performance in children with muscular dystrophy, cerebral palsy, cystic fibrosis, spina bifida, and Rett syndrome. ${ }^{11}$ Hydrotherapy is based on the principles of hydrodynamics (buoyancy, relative density, viscosity, resistance, hydrostatic pressure, turbulence, and flow) and is thought to provide multiple sensory stimuli through water temperature, weight relief, and vestibular input. The properties of water assist active movement, provide postural support, and promote relaxation of spastic muscles, improved circulation, and strengthening, allowing a variety of fundamental motor skills to be performed, relative to an individual's skill level. ${ }^{6,13}$ Aquatic activities also provide opportunities for social interaction and play, which can facilitate language development and improve self-esteem, self-awareness, and sense of accomplishment. ${ }^{5}$

In recent years, there has been increased focus on specific hydrotherapy interventions for people with disabilities. For example, the Halliwick method ${ }^{14}$ was developed by James McMillan in the late 1940 s, to introduce people with disabilities to the aquatic environment. Using the principles of hydrodynamics and body mechanics, the Halliwick method comprises four phases: adjustment to water, rotations, control of movement in water, and movement in water. ${ }^{15,16}$ Application of the Halliwick method follows a 10-point program. ${ }^{17}$

Anecdotally, in clinical practice, the Halliwick method is often the basis of many hydrotherapy programs, although it is adapted to meet the individual needs of patients/clients.

Research into the effects of a hydrotherapy program on children with increased needs is growing. Fragala-Pinkham et $\mathrm{al}^{18}$ found that a 14 -week hydrotherapy exercise program improved cardiorespiratory endurance and fitness in children with disabilities, including ASDs. $\operatorname{Pan}^{7}$ found improvements of muscular strength and endurance in children with ASDs, following hydrotherapy. Motor performance was increased in children with ASDs, following a 12-week hydrotherapy program, in a study by Yanardag et al..$^{5}$

Bumin et $\mathrm{al}^{19}$ found a decrease in stereotypical movements, in a child with stage III Rett Syndrome, after an 8-week, Halliwick-based hydrotherapy program: hand skills, balance, gait, and interaction with her environment improved, while her hyperactive behavior and anxiety was reduced. Pan $^{7}$ found significant improvements in self-confidence, social performance, and relationships, in children with ASDs, as reported by parents.

A survey of 18 occupational therapists using hydrotherapy to treat young children with ASDs reported a substantial increase in attention, muscle strength, balance, toleration of touch, initiation and maintenance of eye contact, and social participation. ${ }^{11}$ Additionally, children with ASDs and their parents described aquatic therapy, water play skills, and swimming as enjoyable. ${ }^{5}$

The aim of our review was to investigate the effectiveness of hydrotherapy interventions in improving the social interaction and behaviors of children with ASDs. Improvements in these areas would extend the application of hydrotherapy beyond physical impairments, in children with ASDs.

\section{Methods}

\section{Search strategy}

This review was conducted and reported in line with the Preferred Reporting Items for Systematic Reviews and MetaAnalyses (PRISMA) Statement. ${ }^{20}$ In March 2013, a search of six electronic databases was conducted collaboratively by the two reviewers. The searched databases included: Cochrane (all available dates), Cumulative Index to Nursing and Allied Health Literature (CINAHL) (January 1982- March 2013), PsycINFO (January 1840- March 2013), Embase (January 1980- March 2013), MEDLINE ${ }^{\circledR}$ (January 1966- March 2013), and Academic Search Premier (January 1975-March 2013). Only studies published in English were included. No date restrictions were applied as there were no known published systematic reviews. Table S1 outlines the search question and keywords used in the search strategy. The reference lists of all the included studies were reviewed to elicit any relevant studies that were not located by the electronic search.

\section{Study design}

All forms of primary and secondary evidence were searched for, including systematic reviews, retrospective studies, randomized control trials (RCTs), controlled clinical trials (CCTs), and case studies. 


\section{Population}

Studies were included for consideration if the participants were aged 3-18 years, of either sex, and diagnosed with ASDs (including Asperger's syndrome and pervasive developmental disorders), irrespective of the diagnostic criteria used. Participants had to be at a high-functioning level to participate in a hydrotherapy intervention. Exposure to prior aquatic experience or other prior interventions did not result in any exclusion of participants.

\section{Intervention}

Studies were included if the intervention described a hydrotherapy program, such as the Halliwick method. ${ }^{14}$ Studies describing interventions of swimming and other water sports, water play, and land-based aquatic play were not considered.

\section{Outcome measures}

Studies were included if they utilized outcome measures that assessed social interaction and behavior through questionnaire or observation, such as the School Social Behavior Scales (SSBS-2), observational stereotypical movement analysis, or Computerized Evaluation Protocol of Interactions in Physical Education (CEPI-PE). Possible adverse effects from hydrotherapy interventions include fatigue due to increased physical activity and regression of social or motor behaviors, due to change in routine or environment. Such adverse effects would have ethical and clinical considerations. The adverse effects were considered.

\section{Search of literature}

A review protocol was established and the databases searched. The results of the searches were pooled, and duplicates removed. Potential studies were identified by evaluating the title and abstract to determine their appropriateness, following the Population, Intervention, Comparator and Outcome (PICO) criteria (as described in Table 1). The relevant studies were independently reviewed in full by the two reviewers to determine their inclusion, based on the predetermined criteria and the evidence hierarchy. Any disagreement was resolved with discussion or, when needed, through consultation with a third party.

\section{Quality assessment}

The methodological quality of the included studies was independently assessed by the two reviewers. The hierarchy of evidence for all the studies was assessed according to the National Health and Medical Research Council (NHMRC) designation of levels of evidence. ${ }^{21}$ The McMaster Critical
Table I Search strategy (PICO criteria)

\begin{tabular}{ll}
\hline & Definition \\
\hline Population & Children aged 3-8 years diagnosed with ASDs \\
Intervention & Hydrotherapy program, such as the "Halliwick method"/4 \\
Comparator & N/A \\
Outcome & Assessing social interaction and behavior through \\
& questionnaire or observation \\
\hline
\end{tabular}

Abbreviations: ASDs, autism spectrum disorders; N/A, not available; PICO, Population, Intervention, Comparator and Outcome.

Review Form for Quantitative Studies ${ }^{22}$ was used for all RCTs, CCTs, and single case study designs.

\section{Data extraction and analysis}

The data was extracted by the two reviewers and collated into excel spread sheets, including information related to: study design; participants' information (age, sex, and diagnosis); intervention components; intervention duration; dose and frequency of the intervention; experimental design and method randomization; outcome measures; statistical analyses; and the results of pre- and postanalysis or other appropriate analysis. Any disagreement was resolved through discussion and consultation with a third party, where needed.

The collected data were compared, but due to the small number of studies and variability in the outcome measures, a meta-analysis was not appropriate. Therefore, a narrative analysis was performed by the two reviewers.

\section{Body of evidence framework}

The NHMRC body of evidence framework was used in the interpretation of findings and the implications for clinical practice. The framework evaluated the included studies along five dimensions of evidence. The five components of the framework assessed: 1) the quantity, quality, and level of evidence; 2) consistency; 3) clinical impact; 4) generalizability; and 5) applicability to the Australian health care setting - this latter was not included in this review as the intervention may be implemented in an international population. Based on this framework, evidence-based recommendations for practice and research could be made.

\section{Results Search results}

The search strategy returned 61 total "hits," 43 of these were potentially relevant studies. After removal of the duplicates and review of the full-text versions, a total of four studies were identified as being eligible for review. The search strategy is outlined in Figure 1. Potentially relevant articles that 


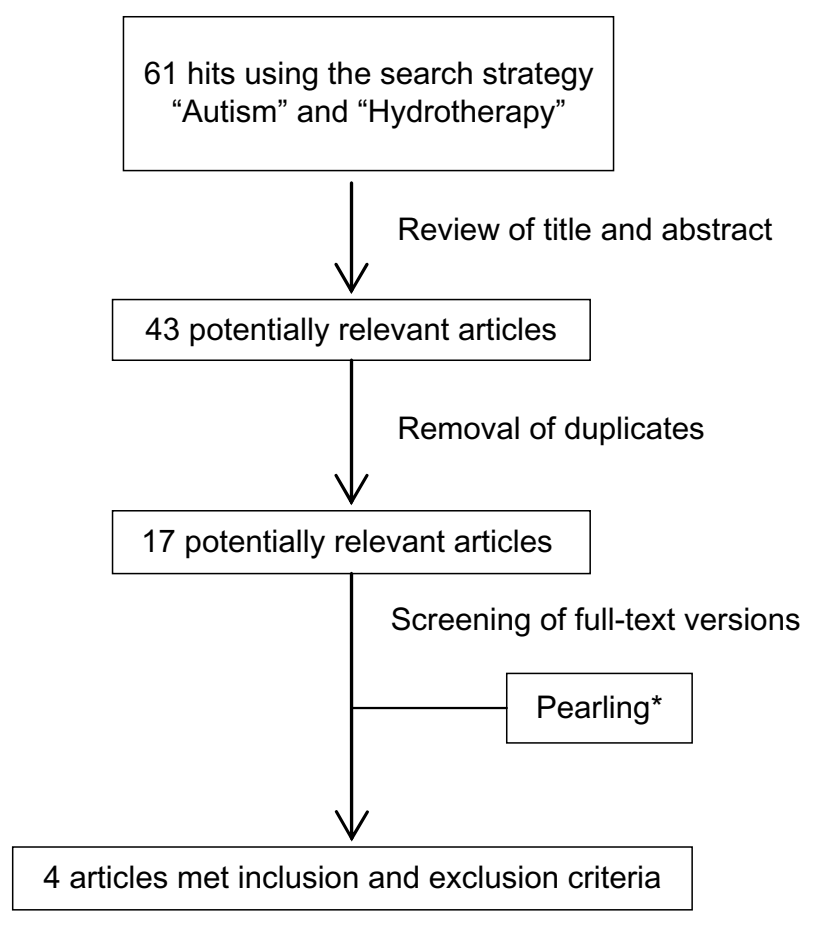

Figure I Consort diagram.

Notes: *Pearling refers to a review of the reference lists of identified studies in search of any additional studies that might not have been sourced through the literature search. It is also termed secondary searching.

fulfilled initial inclusion criteria were subsequently excluded for the following reasons:

- Intervention was a swimming program not hydrotherapy

- Diagnosis of Rett syndrome

- Outcome measures did not assess social interactions and behaviors (ie, only assessed physical fitness or motor skill performance)

- No valid outcome measure used

- Not an experimental research design

- Full-text article not published in English.

\section{Methodological quality}

The included studies were assessed for methodological quality using the NHMRC designation of levels of evidence and the McMaster Critical Review Form for Quantitative Studies. The results of the critical appraisal are outlined in Table 2. Two studies were rated as NHMRC level III and two were rated as level IV. Two of the studies received moderate McMaster scores $^{23,25}$ whereas the two others received low scores. ${ }^{15,24}$

Studies received lowered McMaster scores because they were deficient with respect to random allocation of subjects, concealed allocation, homogeneity of sample, blinding of subjects and therapists, reporting of dropouts, justification of sample size, and addressing contamination and cointervention. Two of the studies did not address the
Table 2 Levels of evidence and methodological quality of included studies

\begin{tabular}{lll}
\hline Study & $\begin{array}{l}\text { NHMRC designation } \\
\text { of levels of evidence }\end{array}$ & $\begin{array}{l}\text { McMaster critical } \\
\text { appraisal tool score }\end{array}$ \\
\hline Yilmaz et al ${ }^{15}$ & IV & $6 / 13(46 \%)$ \\
Pan $^{24}$ & III-3 & $10 / 14(71 \%)$ \\
Ennis $^{25}$ & IV & $6 / 14(43 \%)$ \\
${\text { Chu and } \text { Pan }^{26}}^{2}$ & III-2 & $11 / 14(79 \%)$ \\
\hline
\end{tabular}

Abbreviation: NHMRC, National Health and Medical Research Council.

analysis method appropriately, and one study did not report dropouts. Only one study included blinding of measurers. One study did not describe the intervention in detail, and two did not give details on the validity and reliability of outcome measures. Table 2 provides an overview of the NHMRC designation of levels of evidence and the critical appraisal scores for the individual studies.

\section{Study characteristics}

The included studies were published from 2004-2012. They comprised one single-subject case study with pre- and postmeasurements; ${ }^{15}$ one controlled, single-blinded, withinparticipant repeated measures crossover study with 10 weeks of follow up; ${ }^{23}$ one (pre- and postmeasure) case series; ${ }^{24}$ and one study that included three intervention arms (trained peer assistance, trained sibling assistance, or untrained assistance [the controls]). ${ }^{25}$ One study was conducted in Turkey, ${ }^{15}$ two in Taiwan, ${ }^{23,25}$ and one in the US. ${ }^{24}$

\section{Participant characteristics}

Table 3 outlines the characteristics of each study. The number of participants in the studies was one, eleven, 16, and 42 . The participants' age ranged from 3-12 years. Ethnicity was not reported by any of the studies. The diagnoses included highfunctioning autism and Asperger's syndrome. The diagnostic criteria were not specified for two of the articles; ${ }^{15,24}$ the other two ${ }^{23,25}$ sought independent diagnosis according to the DSM-IV criteria. One study excluded individuals with intellectual disability as a concurrent condition, another excluded participants with a history of previous or current psychiatric or neurological disorder aside from ASD, and one study included participants with comorbidities such as spina bifida and cerebral palsy.

\section{Types of intervention}

All four studies based their hydrotherapy intervention on the Halliwick method. Two of the studies used the Humphries' Assessment of Aquatic Readiness assessment instruction, which was developed in accordance with the foundations of the Halliwick method. The protocol used by Ennis ${ }^{24}$ included 
Table 3 Study characteristics

\begin{tabular}{|c|c|c|c|c|c|c|c|}
\hline Study & $\begin{array}{l}\text { Research } \\
\text { design }\end{array}$ & $\begin{array}{l}\text { Age } \\
\text { (yrs) }\end{array}$ & $\mathbf{N}$ & Diagnosis & Intervention & $\begin{array}{l}\text { Outcome } \\
\text { measure }\end{array}$ & Results \\
\hline $\begin{array}{l}\text { Yilmaz } \\
\text { et } \text { al }^{15}\end{array}$ & Case study & 9 & I & Not specified & $\begin{array}{l}\text { Hydrotherapy program } \\
\text { using Halliwick method }{ }^{14} \\
10 \text { wks, } 3 \text { times/wk, } 60 \text { min }\end{array}$ & $\begin{array}{l}\text { Video analysis } \\
\text { of behaviors } \\
\text { before and after } \\
\text { intervention }\end{array}$ & $\begin{array}{l}\text { Decrease in stereotypical } \\
\text { movements } \\
\text { Increase response to } \\
\text { stimuli }\end{array}$ \\
\hline $\operatorname{Pan}^{24}$ & $\mathrm{CCT}$ & $6-9$ & 16 & $\begin{array}{l}\text { DSM-IV criteria } \\
\text { High-functioning } \\
\text { autism }(n=8) \\
\text { Asperger's } \\
\text { syndrome }(n=8)\end{array}$ & $\begin{array}{l}\text { Water exercise swimming } \\
\text { program based on HAAR, } \\
\text { according to Halliwick } \\
10 \text { wks, } 2 \text { times/wk, } 90 \text { min } \\
21 \text { wks total: } 10 \text { wks } \\
\text { WESP, I0 wks control, } \\
\text { I wk transition }\end{array}$ & SSBS-2 & $\begin{array}{l}\text { Improvements in social } \\
\text { interactions and behavior } \\
\text { Maintained after } 10 \\
\text { weeks of follow up }\end{array}$ \\
\hline Ennis $^{25}$ & Case series & $3-9$ & $\begin{array}{l}\text { II } \\
5 \text { dropouts }\end{array}$ & $\begin{array}{l}\text { ASD, including } \\
\text { Asperger's syndrome } \\
\text { and PDD-NOS } \\
\text { Secondary diagnoses } \\
\text { included spina bifida } \\
\text { and cerebral palsy }\end{array}$ & $\begin{array}{l}\text { Aquatic program } \\
10 \text { wks, } 2 \text { times/wk, } 60 \text { min }\end{array}$ & Peds-QL & $\begin{array}{l}\text { Improvement in Peds-QL } \\
\text { total scores } \\
\text { Individual improvements } \\
\text { in social skills, school } \\
\text { functioning, and } \\
\text { emotional functioning }\end{array}$ \\
\hline $\begin{array}{l}\text { Chu and } \\
\operatorname{Pan}^{26}\end{array}$ & CCT & $7-12$ & $\begin{array}{l}42 \\
21 \mathrm{ASD}\end{array}$ & $\begin{array}{l}\text { DSM-IV criteria } \\
\text { High-functioning } \\
\text { autism }(n=14) \\
\text { Asperger's syndrome } \\
(n=7)\end{array}$ & $\begin{array}{l}\text { Aquatic program based } \\
\text { on HAAR according } \\
\text { to Halliwick } \\
16 \text { wks, } 2 \text { times/wk, } 60 \mathrm{~min}\end{array}$ & CEPI-PE & $\begin{array}{l}\text { All children with ASD } \\
\text { showed improvements } \\
\text { in physical and social } \\
\text { behaviors (higher with } \\
\text { trained peer/sibling } \\
\text { assistance) } \\
\text { Decrease in physical } \\
\text { interactions with } \\
\text { teachers and some } \\
\text { physical interactions with } \\
\text { peers/siblings }\end{array}$ \\
\hline
\end{tabular}

Abbreviations: ASD, autism spectrum disorder; CCT, controlled clinical trial; CEPI-PE, Computerized Evaluation Protocol of Interactions in Physical Education; DSM, Diagnostic and Statistical Manual of Mental Disorders; HAAR, Humphries' Assessment of Aquatic Readiness; PDD-NOS, pervasive developmental disorder - not otherwise specified; Peds-QL, Pediatric Quality of Life Inventory ${ }^{\mathrm{TM}}$; SSBS-2, School Social Behavior Scales; WESP, water exercise swimming program.

specific skill performance and free time. Table 3 specifies the duration of each program. The hydrotherapy programs consisted of two to three sessions per week, over 10-16 weeks; the individual sessions ranged from 60-90 minutes. Progression of the aquatic activities was paced individually, over the course of the program.

The study by Chu and $\operatorname{Pan}^{25}$ had three intervention arms: a peer-assisted group (PG), a sibling-assisted group (SG), and a control group (CG) participating in the intervention concurrently. $\operatorname{Pan}^{23}$ had two intervention groups participating in a cross-over design: during the first 10 weeks group A received hydrotherapy while group B participated in their usual activities, this was followed by a 1 -week transition, then another 10 weeks in which group B received hydrotherapy and group A participated in their usual activities. When not receiving hydrotherapy, each group participated in their regular treatment and activities. Ennis $^{24}$ conducted two consecutive 10-week interventions. In that study, six children completed one 10-week intervention, and three completed the two 10 -week interventions.

\section{Measures}

The outcome measures used in each study are identified in Table 3. One study ${ }^{15}$ assessed participants' behaviors, including: stereotypical movement analysis (spinning, swinging, and delayed echolalia) and no or late (within 5 seconds) reaction to stimulus. The assessment was based on an analysis of 45-minute-long video camera footage. Another study ${ }^{23}$ used the SSBS-2 to assess social behaviors. The SSBS-2 is a classroom teacher-rated, norm-referenced standardized instrument that assesses social competencies, such as peer relations, self-management/compliance, and academic behavior, as well as antisocial behavior, such as hostile/irritable, antisocial/aggressive, and defiant/disruptive behaviors. The third study ${ }^{24}$ used the Pediatric Quality of Life Inventory ${ }^{\mathrm{TM}}$ (Peds-QL) parent survey to assess quality of life issues; the results of the Peds-QL were reported as total scores and as physical functioning, emotional functioning, social functioning, and school functioning subscale scores. The fourth study ${ }^{25}$ used the CEPI-PE to assess physical and social interaction 
behaviors. This assessment was focused on four subcategories of interactions: between the child with ASD and the instructor; between the child with ASD and their designated peer/ sibling; between the child with ASD and the other children with ASD; and between the child with ASD and the other typically developing peers/siblings in the group. The social interaction behaviors could be voluntary or spontaneous, or verbal or nonverbal. The physical interaction behaviors consisted of active engagement in individual or group aquatic activities. Each 50-minute observation session was recorded on videotape and analyzed.

All the studies measured participants before and after the hydrotherapy interventions. One arm of the $\operatorname{Pan}^{23}$ study was measured after a 10 -week follow-up period, due to its crossover design. Two studies ${ }^{15,24}$ did not identify the validity or reliability of the outcome measure. The other two ${ }^{23,25}$ reported a high degree of validity and reliability of their respective outcome measures.

\section{Outcome}

Table 4 provides a summary of results from the included studies. The summarized findings indicate that hydrotherapy had a positive impact on the social interactions and behaviors in children with ASD.

Yilmaz et $\mathrm{al}^{15}$ reported a reduction in participants' stereotypical movements following the 10-week hydrotherapy intervention. The duration of three stereotypical movements was measured before and after the hydrotherapy intervention (and was decreased for all three): the duration of swinging was 7 minutes and 5 minutes, respectively; the duration of spinning was 2 minutes and 0 minutes, respectively; and the duration of delayed echolalia was 4 minutes and 2 minutes, respectively. The researchers also found an increase in the participants' reaction to stimuli. The number of nonreactions to stimuli decreased, from 12 to 6 , at the pre and postintervention 45-minute behavioral analyses, respectively.
$\operatorname{Pan}^{23}$ reported significant improvements $(P<0.01)$ in the participants' social interactions and behaviors following each group's hydrotherapy intervention. Both groups had significant improvements $(P<0.01)$ in hostile/irritable and antisocial behavior. Further improvement $(P<0.01)$ in hostile/irritable behavior was seen at the 10 week follow-up assessment of Group A (no follow-up was done for Group B). Group A also demonstrated significant improvements $(P<0.01)$ in academic behavior, aggressive behavior, and defiant/disruptive behavior, while group B showed significant improvement $(P<0.01)$ in social competence. There was no overall between-group difference in outcomes.

In the study by Ennis, ${ }^{24}$ there was a decrease in the Peds-QL score in $67 \%$ of children, indicating positive changes across the areas of social, emotional, school, and physical function. These positive changes were seen in most of the Peds-QL subscores, although this was to varying degrees: $83 \%$ of children showed an increase in social functioning, 50\% showed an increase in school functioning, $67 \%$ showed an increase in physical functioning, and $50 \%$ showed an increase in emotional functioning. In addition, in one participant, there was no change in either the emotional or school subscale over the 10 -week intervention.

In addition to these results, the three participants who completed both of the 10-week interventions showed continued improvements in most subscales: 67\% showed improved total Peds-QL scores (one showed no change), 67\% showed improvement in physical functioning, 100\% showed an improvement in emotional functioning, 33\% showed improvement in social functioning (one showed no change), and 100\% showed an improvement in school functioning.

Chu and $\operatorname{Pan}^{25}$ showed improved social interactions with peers/siblings and teachers and reduced physical interactions with teachers, in all groups, during the group activity time. The untrained $\mathrm{CG}$ group showed improved physical interactions with peers/siblings, whereas the PG- and SG-assisted groups

Table 4 Summary of results

\begin{tabular}{|c|c|c|c|c|c|c|c|c|}
\hline \multirow[t]{2}{*}{ Study } & \multicolumn{8}{|c|}{ Summarized findings on the effect of hydrotherapy on social interactions and behaviors } \\
\hline & $\begin{array}{l}\text { Stereotypical } \\
\text { movements }\end{array}$ & $\begin{array}{l}\text { Response } \\
\text { to stimuli }\end{array}$ & $\begin{array}{l}\text { Social } \\
\text { interactions }\end{array}$ & $\begin{array}{l}\text { Antisocial } \\
\text { behaviors }\end{array}$ & $\begin{array}{l}\text { Physical } \\
\text { interactions - } \\
\text { peers/siblings }\end{array}$ & $\begin{array}{l}\text { Physical } \\
\text { interactions - } \\
\text { teachers }\end{array}$ & $\begin{array}{l}\text { School behavior } \\
\text { and academic } \\
\text { performance }\end{array}$ & $\begin{array}{l}\text { Emotional } \\
\text { functioning }\end{array}$ \\
\hline $\begin{array}{l}\text { Yilmaz } \\
\text { et al }\left.\right|^{15}\end{array}$ & $\downarrow(+)$ & $\uparrow(+)$ & & & & & & \\
\hline $\operatorname{Pan}^{24}$ & & & $\uparrow(+)$ & $\downarrow(+)$ & & & $\uparrow(+)$ & \\
\hline Ennis $^{25}$ & & & $(+)$ & $(+)$ & & & $(+)$ & $(+)$ \\
\hline Chu and & & & $\uparrow(+)$ & & Mixed & $\downarrow( \pm)$ & & \\
\hline $\operatorname{Pan}^{26}$ & & & & & & & & \\
\hline
\end{tabular}


showed a decrease. Additionally, the PG- and SG-assisted groups showed improvement in social interactions with other peers/siblings and other children with ASD during this time.

During the individual activity time, the CG group (with untrained peers/siblings) showed no significant improvements, whereas both the PG- and SG-assisted groups (which had trained peers/siblings) showed improved physical interactions with peers, improved social interactions with peers and teachers, and reduced physical interactions with teachers.

Thus, the children with ASD who were assisted by trained peers or siblings had significantly greater improvement in social and physical interactions compared with those who had untrained peers or siblings assisting them.

\section{NHMRC body of evidence framework}

The analysis of the results, using the NHMRC body of evidence framework, is described in Table 5. Given that the overall body of evidence was limited in size and had methodological flaws, the results of this review should be applied with caution. Despite positive outcomes being reported in every study, there are several factors that were unclear or were inadequately addressedthe grade of evidence was lowered due to these inconsistencies in the current evidence base. Therefore, the implementation of recommendations should be made with caution.

\section{Discussion}

The four studies included in the systematic review investigated the effect of a hydrotherapy program on the social interactions and behaviors of children aged 3-12 years who were diagnosed with high functioning autism or Asperger's syndrome. In all four studies, the respective hydrotherapy intervention, each underpinned by the Halliwick method, resulted in improvements in social interactions and behaviors. Follow-up studies showed that at 10 weeks postintervention, there was a carryover effect, and further improvement after a second round of intervention was also observed.

Table 5 NHMRC body of evidence framework

\begin{tabular}{|c|c|c|}
\hline Component & Grade & Comments \\
\hline \multirow[t]{5}{*}{ Evidence base } & $D-$ poor & Quantity: total of four studies \\
\hline & Level IV studies, or level I & Total participants: 49 children with ASD (5 dropouts) \\
\hline & to III studies with high risk of bias & Level III: two studies \\
\hline & & Level IV: two studies \\
\hline & & Quality: low \\
\hline \multirow[t]{5}{*}{ Consistency } & $D-$ poor & Multiple study designs \\
\hline & Evidence is inconsistent & While all participants were diagnosed with ASD, the prevalence of \\
\hline & & comorbidities was not addressed or was unclear \\
\hline & & Multiple and varied outcome measures \\
\hline & & Statistical analysis adequate in two of the four studies \\
\hline \multirow[t]{11}{*}{ Clinical impact } & $D-$ poor & One study reported effect size and for others, the effect size could not be \\
\hline & Slight or restricted & calculated due to insufficient data \\
\hline & & While intervention protocol was adequately described, no justification for \\
\hline & & parameters or developmental process were outlined \\
\hline & & Consistent findings for only one outcome (social interaction), with varied \\
\hline & & outcomes for other measures \\
\hline & & Minimal reporting of outcomes relating to academic performance, behaviors, \\
\hline & & and physical and emotional functioning \\
\hline & & No adverse effects were reported but reasons for dropouts not addressed \\
\hline & & Only one study undertook follow-up (for up to 10 weeks) and other studies \\
\hline & & did not report any ongoing follow-up data \\
\hline \multirow[t]{6}{*}{ Generalizability } & $B-\operatorname{good}$ & Population studied in the evidence base is similar to the target population \\
\hline & Population(s) studied in body & Age range $6-12$ years \\
\hline & of evidence is/are similar & Samples included in the studies were high functioning individuals \\
\hline & to the target population & The current evidence base lacks clarity in terms of reporting of comorbidities \\
\hline & & and cointerventions and its impact on outcomes, and small sample sizes that \\
\hline & & did not represent the autism spectrum and did not include any teenagers \\
\hline Grade of & $D-$ poor & Limited number of studies were identified from the literature \\
\hline \multirow[t]{5}{*}{ recommendation } & Body of evidence is weak, & Overall, these studies were low level and were of low quality \\
\hline & and recommendation should & While some congruency in findings across all four studies, the current \\
\hline & be applied with caution & evidence base lacks clarity in terms of the prevalence of comorbidities, poor \\
\hline & & justification of parameters and developmental processes, differing outcome \\
\hline & & measures, and lack of long-term follow-up \\
\hline
\end{tabular}

Abbreviations: ASD, autism spectrum disorder; NHMRC, National Health and Medical Research Council. 
The results of this review correspond with previous small-scale research evidence reporting the benefits of hydrotherapy programs on social interactions and behaviors, in children with ASDs. ${ }^{9,11,26-31}$ Chu and $\operatorname{Pan}^{25}$ have suggested these improvements may be due to enforced social interaction with peers or siblings through the constructs of the hydrotherapy program and guidance of the instructor. Children with ASDs benefit from receiving constant individual attention from the instructor and from observing the positive social interactions of others during hydrotherapy sessions. ${ }^{23,25}$ Lessons from clinical practice indicate that the potential benefits from hydrotherapy include: stimulation of vocalization and language; improved toleration of touch; encouragement of eye contact, and improved confidence. ${ }^{11,30}$ While not the focus of hydrotherapy sessions, these benefits may have holistic effects and hence translate to improved relationships with peers and siblings and increased social acceptance. ${ }^{25}$

\section{Effect on social interactions}

\section{and behaviors}

The decreased physical interaction with teachers observed by Chu and $\operatorname{Pan}^{25}$ may not necessarily be a negative result. As discussed by Chu and Pan, this change may be interpreted as positive in that the child with ASD is less reliant on adult interaction and more willing to interact with his/her peers. Vonder Hulls et $\mathrm{l}^{11}$ discussed similar findings in their research, suggesting that a decrease in children with ASDs asking teachers for help could be interpreted positively as a sign that the child is gaining confidence and independence, rather than as diminishing interactions.

\section{Effect of age, sex, ethnicity}

The results from this review are likely to be applicable to the broader ASD population. However, the variable presentation of the ASD population in social, behavioral, and physical domains could affect outcome, as discussed in Vonder Hulls et al. ${ }^{11}$ Thus, the four reviewed studies included only high-functioning individuals, and the effectiveness at the lower-functioning end of the spectrum is unknown. Within the ASD population, age may not be a limiting factor as social, behavioral, and physical impairments can continue through life. There is also the possibility of extending these results to application in the management of other neurodevelopmental disorders involving social interaction and behavioral impairments.

\section{Interventions}

The structure of the hydrotherapy sessions was consistent across the four studies, and all the interventions were based on the principles of the Halliwick method. The intensity of the intervention was comparable between the studies: three of the four studies were of 60 minutes duration, one was 90 minutes; two of the four studies conducted sessions twice a week, and the third conducted sessions three times a week (the fourth was not defined); hydrotherapy interventions were held over 10-16 weeks. These designs are commonly employed in hydrotherapy interventions. ${ }^{5,7-9,11,18,31}$

One study ${ }^{25}$ implemented the assistance of trained or untrained typically developing peers and siblings in the hydrotherapy program. This was a unique concept, and greater improvements were seen in the children with ASDs who were assisted by a trained peer or sibling. Similar results have been found in land-based interventions utilizing trained typically developing peers or siblings. ${ }^{32-34}$

\section{Limitations}

As with any research, there are some limitations of this systematic review. Despite considerable searching of the literature, we were able to locate only four studies that met the inclusion criteria. The included studies had low-level research designs (level III or IV) and had some issues of methodological quality. The methodological concerns in areas such as sampling techniques, allocation of subjects to treatment groups, homogeneity of treatment groups, and blinding may be difficult to address due to the population of interest and the intervention administered (thus, for example, efforts were made to control for the variable presentation of ASDs rather than to randomly allocate the participants to treatment groups). The sample sizes were generally small and lacking justification, possibly due to the poor availability of children with ASDs to participate in the studies. The breadth of the social and behavioral impairments in children with ASDs impedes standardization of the scope and intent of outcome measures utilized in studies; given the diversity of the outcome measures used and heterogeneity in sampling and interventions, a direct comparison of results between studies was not possible.

There also exist possible limitations in implementing the intervention in question. Access to hydrotherapy services is likely to be influenced by a number of factors, such as local health care models of service delivery and funding arrangements. These factors need to be taken into account when considering hydrotherapy as an option.

\section{Conclusion}

\section{Implications for clinical practice}

There is an increasing body of evidence to support the widely held view that a hydrotherapy intervention, underpinned by the Halliwick approach, may be effective in improving the social interactions and behaviors of children with ASDs. 
Further, it has been identified that the improvements in social interactions and behaviors may be further enhanced by the use of trained peers or siblings to assist the child with ASDs during the hydrotherapy intervention. However, while hydrotherapy may be considered as an adjunct treatment for the problematic social interactions and behaviors in children with ASDs, it must be recognized that the current evidence base also suffers from important methodological issues.

\section{Implications for future research}

An emerging body of evidence has been identified to support the use of a hydrotherapy intervention for improving the social interactions and behaviors of children with ASDs. However, significant research limitations have also been recognized, highlighting the need for further research. Future studies could address the effect of age, the intensity of intervention, class size, and student-teacher ratio, and the feasibility of applying hydrotherapy for individuals at the lower-functioning end of the autism spectrum. Future studies may also improve on the current evidence by implementing a standardized outcome measure. Sampling methods could be improved, to increase the sample size derived from representative population, and longterm follow-up undertaken, to capture the sustainability and durability of outcomes. It would also be beneficial to determine the effect of hydrotherapy as a stand-alone intervention compared with other interventions or combination of interventions, and to determine the effect of the parameters underpinning the hydrotherapy program. Additionally, future research should integrate the recently released DSM-V diagnostic criteria into the sampling strategies and explore the impact of this approach to diagnosis on the selection of relevant interventions.

\section{Author contributions}

RM and MP conceptualized the topic, developed the search strategy, carried out the search of literature and data extraction, and contributed equally to the development of the final draft. SK instituted the use of the NHMRC body of evidence framework and revised the draft. All the authors contributed toward data analysis, revision of the manuscript and are accountable for all aspects of the work.

\section{Acknowledgment}

We would like to thank Dr Lucylynn Lizarondo for her prompt and helpful guidance throughout the initial stages of this review.

\section{Disclosure}

The lead author (RM) is currently employed by a communitybased children's service organization that provides services to children living with disabilities and special needs, as well as support for their families and carers. The authors report no other conflicts of interest.

\section{References}

1. Bölte S, Westerwald E, Holtmann M, Freitag C, Poustka F. Autistic traits and autism spectrum disorders: the clinical validity of two measures presuming a continuum of social communication skills. J Autism Dev Disord. 2011;41(1):66-72.

2. Prior M. Is there an increase in the prevalence of autism spectrum disorders? J Paediatr Child Health. 2003;39(2):81-82.

3. Kong X, Chen L, Wang X. Future directions in autism treatment. $N A$ J Med Sci. 2012;5(3):185-188.

4. Matson JL, Kozlowski AM. The increasing prevalence of autism spectrum disorders. Res Autism Spectr Disord. 2011;5(1):418-425.

5. Yanardag M, Akmanoglu N, Yilmaz I. The effectiveness of video prompting on teaching aquatic play skills for children with autism. Disabil Rehabil. 2013;35(1):47-56.

6. Lee J, Porretta DL. Enhancing the motor skills of children with autism spectrum disorders. JOPERD. 2013;84(1):41-45.

7. Pan CY. The efficacy of an aquatic program on physical fitness and aquatic skills in children with and without autism spectrum disorders. Res Autism Spectr Disord. 2011;5(1):657-665.

8. Fragala-Pinkham MA, Haley SM, O’Neil ME. Group swimming and aquatic exercise programme for children with autism spectrum disorders: a pilot study. Dev Neurorehabil. 2011;14(4):230-241.

9. Fragala-Pinkham M, O’Neil ME, Haley SM. Summative evaluation of a pilot aquatic exercise program for children with disabilities. Disabil Health J. 2010;3(3):162-170.

10. Reid G, O'Connor J. The autism spectrum disorders: activity selection, assessment, and programme organization. Palaestra. 2003;19(1):20-27, 58.

11. Vonder Hulls DS, Walker LK, Powell JM. Clinicians' perceptions of the benefits of aquatic therapy for young children with autism: a preliminary study. Phys Occup Ther Pediatr. 2006;26(1-2):13-22.

12. Field T, Lasko D, Mundy P, et al. Brief report: autistic children's attentiveness and responsivity improve after touch therapy. $J$ Autism Dev Disord. 1997;27(3):333-338.

13. Dumas H, Francesconi S. Aquatic therapy in pediatrics: annotated bibliography. Phys Occup Ther Pediatr. 2001;20(4):63-78.

14. Martin J. The Halliwick Method. Physiotherapy. 1981;67(10): 288-291.

15. Yilmaz I, Yanarda M, Birkan B, Bumin G. Effects of swimming training on physical fitness and water orientation in autism. Pediatr Int. 2004;46(5):624-626.

16. Yilmaz I, Konukman F, Birkan B, Yanardag M. Effects of most to least prompting on teaching simple progression swimming skill for children with autism. Educ Train Dev Disabil. 2010;45(3):440-448.

17. Skinner A, Thomson A. Aquatics therapy and the Halliwick concept. Exceptional Parent. 2008;38(7):76-77.

18. Fragala-Pinkham M, Haley SM, O’Neil ME. Group aquatic aerobic exercise for children with disabilities. Dev Med Child Neurol. 2008;50(11):822-827.

19. Bumin G, Uyanik M, Yilmaz I, Kayihan H, Topçu M. Hydrotherapy for Rett syndrome. J Rehabil Med. 2003;35(1):44-45.

20. Moher D, Liberati A, Tetzlaff J, Altman DG; PRISMA Group. Preferred reporting items for systematic reviews and meta-analyses: the PRISMA statement. Ann Intern Med. 2009;151(4):264-269.

21. Merlin T, Weston A, Tooher R. Extending an evidence hierarchy to include topics other than treatment: revising the Australian 'levels of evidence'. BMC Med Res Methodol. 2009;9:34.

22. Law M, Stewart D, Pollock N, Letts L, Bosch J, Westmorland M. Critical Review Form - Quantitative Studies. Hamilton, ON: McMaster University; 1998. http://www.srs-mcmaster.ca/Portals/20/pdf/ebp/ quanreview.pdf. Accessed December 23,2013. 
23. Pan CY. Effects of water exercise swimming program on aquatic skills and social behaviors in children with autism spectrum disorders. Autism. 2010;14(1):9-28.

24. Ennis E. The effects of a physical therapy-directed aquatic program on children with autism pectrum disorders. Journal of Aquatic Physical Therapy. 2011;19(1):4-10.

25. Chu $\mathrm{CH}$, Pan CY. The effect of peer- and sibling-assisted aquatic program on interaction behaviors and aquatic skills of children with autism spectrum disorders and their peers/siblings. Res Autism Spectr Disord. 2012;6(3):1211-1223.

26. Killian KJ, Joyce-Petrovich RA, Menna L, Arena SA. Measuring water orientation and beginner swim skills of autistic individuals. Adapt Phys Activ Q. 1984;1(4):287-295.

27. Huettig C, Darden-Melton B. Acquisition of aquatic skills by children with autism. Palaestra. 2004;20(2):20-46.

28. Harland K. A Will of His Own: Reflections on Parenting a Child with Autism. Revised edition. London: Jessica Kingsley Publishers; 2007.
29. Best JF, Jones JG. Movement therapy in the treatment of autistic children. Aust Occup Ther J. 1974;21(2):72-86.

30. Dulcy F. An integrated developmental aquatic program (IDAP) for children with autism. National Aquatics Journal. 1992;8(2):7-10.

31. Yilmaz I, Birkan B, Konukman F, Erkan M. Using a constant time delay procedure to teach aquatic play skills to children with autism. Educ Train Dev Disabil. 2005;40(2):171-182.

32. Weiss MJ, Harris SL. Teaching social skills to people with autism. Behavior Modification. 2001;25(5):785-802.

33. Tsao LL, Odom SL. Sibling-mediated social interaction intervention for young children with autism. Topics Early Child Spec Educ. 2006;26(2): 106-123.

34. Bass JD, Mulick JA. Social play skill enhancement of children with autism using peers and siblings as therapists. Psychol Sch. 2007;44(7): $727-735$. 


\section{Supplementary materials}

Table SI Search terms and relevant literature from the database search

\begin{tabular}{|c|c|c|c|c|c|}
\hline Database & Search terms & Mesh/Subject headings & Limiters & Hits & Relevant hits \\
\hline Medline & $\begin{array}{l}\text { Autis* or } \\
\text { ASD or } \\
\text { ASDs or } \\
\text { "Autis* Spectrum } \\
\text { Disorder*" or }\end{array}$ & $\begin{array}{l}\text { exp Child Development Disorders, } \\
\text { Pervasive/or } \\
\text { exp Autistic Disorder/or } \\
\text { exp Asperger Syndrome/ } \\
\text { exp Hydrotherapy }\end{array}$ & $\begin{array}{l}\text { English language and ("all child } \\
\text { ( } 0 \text { to I } 8 \text { years)"; or "preschool } \\
\text { child ( } 2 \text { to } 5 \text { years)" or "child } \\
\text { ( } 6 \text { to I } 2 \text { years)" or "adolescent } \\
\text { (13 to I8 years)") }\end{array}$ & 5 & 4 \\
\hline PsychINFO & $\begin{array}{l}\text { "Pervasive } \\
\text { Development* } \\
\text { Disorder*" or } \\
\text { PDD or } \\
\text { PDDs or } \\
\text { Asperger* } \\
\text { Hydrotherapy OR } \\
\text { Halliwick or }\end{array}$ & $\begin{array}{l}\text { DE "Autism" OR } \\
\text { DE "Pervasive Developmental } \\
\text { Disorders" OR } \\
\text { DE "Aspergers Syndrome" OR } \\
\text { DE "Autism" OR } \\
\text { DE "Rett Syndrome" OR } \\
\text { DE "Aspergers Syndrome" } \\
\text { DE "Hydrotherapy" }\end{array}$ & $\begin{array}{l}\text { English; age groups: } \\
\text { childhood (birth-12 yrs), } \\
\text { preschool age }(2-5 \mathrm{yrs}) \\
\text { school age }(6-12 \mathrm{yrs}) \\
\text { adolescence }(13-17 \mathrm{yrs})\end{array}$ & 7 & 7 \\
\hline EMBASE & $\begin{array}{l}\text { hydro-therapy or } \\
\text { "water therapy" or } \\
\text { "water based" or } \\
\text { "water exercise" or } \\
\text { "aquatic exercise" or } \\
\text { "aquatic based" or }\end{array}$ & $\begin{array}{l}\text { exp Asperger syndrome/or } \\
\text { exp autism/or } \\
\text { exp "pervasive developmental } \\
\text { disorder not otherwise specified"/ } \\
\text { exp Hydrotherapy/ }\end{array}$ & $\begin{array}{l}\text { English language and (child } \\
<\text { unspecified age }>\text { or } \\
\text { preschool child }<1 \text { to } 6 \text { years }> \\
\text { or school child }<7 \text { to } \\
12 \text { years }>\text { or adolescent } \\
<13 \text { to } 17 \text { years }>\text { ) }\end{array}$ & 10 & 9 \\
\hline CINAHL & $\begin{array}{l}\text { "aquatic therapy" or } \\
\text { "pool based" or } \\
\text { "pool therapy" or } \\
\text { "pool exercise" or } \\
\text { balneotherapy or } \\
\text { aquatic }\end{array}$ & $\begin{array}{l}\text { "Child Development Disorders, } \\
\text { Pervasive+" OR } \\
\text { "Asperger Syndrome" OR } \\
\text { "Autistic Disorder" } \\
\text { OR } \\
\text { "Pervasive Developmental } \\
\text { Disorder-Not Otherwise Specified" } \\
\text { "Hydrotherapy+" OR } \\
\text { "Aquatic Exercises" OR } \\
\text { "Water" OR } \\
\text { "Balneology" }\end{array}$ & $\begin{array}{l}\text { Language: English; age } \\
\text { groups: child, preschool: } \\
2-5 \text { years, child: } 6-12 \text { years, } \\
\text { adolescent: } 13-18 \text { years, } \\
\text { all child }\end{array}$ & 10 & 7 \\
\hline COCHRANE & & & & 3 & 3 \\
\hline $\begin{array}{l}\text { Academic } \\
\text { Search Premier }\end{array}$ & & 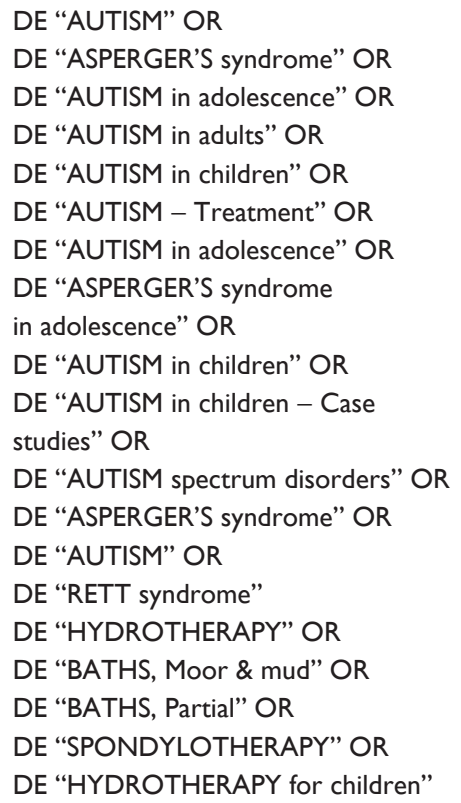 & English language & 26 & 13 \\
\hline
\end{tabular}

Abbreviations: ASD, autism spectrum disorder; Mesh, medical subject headings; PDD, pervasive developmental disorder. 


\section{Publish your work in this journal}

The Journal of Multidisciplinary Healthcare is an international, peerreviewed open-access journal that aims to represent and publish research in healthcare areas delivered by practitioners of different disciplines. This includes studies and reviews conducted by multidisciplinary teams as well as research which evaluates the results or conduct of such teams or

healthcare processes in general. The journal covers a wide range of areas and welcomes submission from practitioners at all levels, from all over the world. The manuscript management system is completely online and includes a very quick and fair peer-review system. Visit http://www.dovepress.com/testimonials.php to read real quotes from published authors.

Submit your manuscript here: http://www.dovepress.com/journal-of-multidisciplinary-healthcare-journal 